ACEVEDO GONZÁLEZ, Horacio Anselmo IES Miguel Delibes

@ horacevedo@yahoo.es

\title{
En busca del origen de la naturaleza idolátrica del nacionalismo (aproximaciones desde la historia mimética y la leyenda negra)
}

In search of the origin of the idolatrous nature of the nationalism (approaches from the mimetic history and the «black legend»)

En este artículo queremos indagar en las circunstancias históricas que propiciaron el origen de la naturaleza idolátrica del nacionalismo. En ese origen encontramos un enfrentamiento de rivalidad cainita con la tendencia católica al universalismo presente desde la Edad Media. Nos vamos a servir para ello de las perspectivas abiertas por la teoría mimética, en concreto por las que ofrece un proyecto que René Girard dejó planteado en su último libro como tarea a llevar a cabo, la Historia Mimética.

PALABRAS CLAVE: Edad Media, leyenda negra, nacionalismo.

In this article we want to investigate the historical circumstances that propitiated the origin of the idolatrous nature of nationalism. In that origin we find a confrontation of Cainite rivalry with the Catholic tendency to universalism present since the Middle Ages. We are going to use the perspectives opened by the mimetic theory for this, in particular for those offered by a project that René Girard left raised in his latest book as a task to be carried out, the Mimetic History.

KEY WORDS: Middle Ages, black legend, nationalism.

Tras el fallecimiento de René Girard, el cierre definitivo de su aportación al pensamiento ha abierto una nueva forma de leer su obra que permite no solo empezar a catalogar las innumerables intuiciones que dejó esbozadas, sino resaltar incluso aquellas que él mismo propuso como tareas que llevar a cabo. A nosotros, por ejemplo, nos llamó en particular la atención el proyecto de elaborar una historia mimética que planteó en Achever Clausewitz, una tarea que definió como «inmenso campo de estudio capaz de ayudarnos a comprender los desafíos de nuestra época» (Girard, 2010, p. 75). 
Hemos de advertir que es el propio Girard quien, en el mismo Achever Clausewitz, no deja de aportar materiales para una posible historia mimética, materiales que deberemos atender para así situar nuestra propia interpretación. Para nosotros, por ejemplo, y a modo de aproximación general, la historia mimética sería algo así como la lectura que la teoría mimética puede ofrecer de la historia universal, un tipo de lectura que, a nuestro parecer, debería seguir un esquema cristiano, pues estaría dominado por la comprensión antropológica del concepto de revelación, que Girard definió como «la verdadera representación del mecanismo victimario que ofrecen los Evangelios» (Girard, 2002, p. 179).

Ya sabemos que dicha comprensión antropológica es la que sirve a la teoría mimética para ilustrar el inicio de la historia humana, ya que su hipótesis acerca del proceso de hominización se basa, precisamente, en dicho mecanismo victimario. Pero esa es también la comprensión que lleva a la teoría mimética a plantear un desenlace catastrófico del devenir humano, tal como le comenta Girard a Benoit Chantre en Achever Clausewitz: «La teoría mimética no solo esclarece el proceso de hominización en los inicios de la humanidad, sino que también descubre la "culminación" de esa hominización como catastrófica» (Girard, 2010, p. 172).

Un desenlace catastrófico del devenir humano como el que presenta el libro que también se títula Revelación, ese último libro de la Biblia cristiana, más conocido por su nombre en griego Apocalipsis y en el que, bajo un lenguaje simbólico, se nos ofrece un relato que bien podría servir de ilustración a los riesgos que la teoría mimética encuentra en la escalada en la violencia que descubre en los análisis que realiza del mundo contemporáneo, violencia que cerraría el ciclo abierto al inicio del tiempo humano por el asesinato primordial y que, según Girard, certificaría el fracaso del cristianismo por frenar dicha catástrofe.

Pero no deja de resultar paradójico entender el catastrófico final de la historia humana como un fracaso del cristianismo cuando ese es precisamente el final del relato que ofrecen las Sagradas Escrituras... Girard no deja de preguntárselo: «¿El cristianismo previó su fracaso apocalíptico? Es razonable pensarlo» (Girard, 2010, p. 84). Es decir, bascula entre pensar que el texto evangélico profetiza el muy previsible apocalipsis (Girard, 2010, p. 41) y el fracaso del cristianismo. Nosotros, en fin, nos preguntamos si esa paradoja tendrá que ver con la ley paradójica a la que parece remitirse a la hora de explicar que, cuanto más nos acerquemos al final, más cerca estaremos de los orígenes: «El cristianismo histórico -y lo que estamos obligados a designar su "fiasco"- no es otra cosa que esa aproximación acelerada del comienzo y del fin de los tiempos» (Girard, 2010, p. 126).

Debemos entender, por tanto, que la atribución de un fracaso al cristianismo no se debe al éxito que supone la representación a la que se refiere antropológicamente el término revelación, sino al desarrollo histórico de un cristianismo que no consigue frenar la revelación del apocalipsis. Pero, preguntamos nosotros, ¿el fracaso dependería del desarrollo histórico del cristianismo o de la comprensión antropológica del desarrollo histórico del cristianismo? o, dicho de otro modo, ¿el proyecto de una historia mimética permitiría aclarar esa ley paradójica o, al menos, ayudar a comprender antropológicamente el desarrollo histórico del cristianismo?

Ante cuestiones de este tipo es lógico empezar a preguntarse por las diferentes perspectivas acerca de la revelación cristiana que ofrecen tanto la teología como la antropología. En este sentido, la obra de Girard parece ofrecernos varias versiones, que van desde una perfecta compatibilidad entre ambas -que vendría dada por el dogma de la encarnación y el misterio de la doble naturaleza, divina y humana, de Jesucristo, compatibilidad que permitiría, 
por ejemplo, concretar la idea a veces un tanto abstracta del pecado original (Girard, 2002, p. 245) - hasta la incompatibilidad derivada de sus distintos orígenes, pues, tal como expone en Achever Clausewitz: «La antropología nace de un fermento romántico y las ciencias de lo religioso solo pueden surgir más allá de las especulaciones teológicas» (Girard, 2010, p. 247).

Si acudimos a la teología católica, por ejemplo, tenemos un ejemplo contemporáneo de reivindicación del tema de la revelación en la famosa constitución dogmática del Vaticano II Dei verbum, donde se aborda la revelación como automanifestación de Dios y se definen, para ello, conceptos tales como Sagrada Escritura, tradición o magisterio.

Girard, por su lado, acude a la tradición teológica para situar la diferencia que, respecto a ella, aporta su lectura antropológica de las Sagradas Escrituras, lectura en la que destaca el tema de la revelación en sus relaciones con el ya mencionado pecado original o con otros conceptos como el de reino de Dios o el de corpus mysticum. No obstante, es necesario destacar un concepto al que presta atención en sí mismo y de manera un tanto singular, estamos hablando del concepto de kathechon, un concepto con vinculaciones teológico-políticas que, aunque está presente en varios de los textos de Girard, resulta misteriosamente ausente en un libro como Achever Clausewitz, que precisamente aborda los temas de la política, la guerra y el apocalipsis.

El kathechon aparece en la segunda epístola de san Pablo a los tesalonicenses con el significado de fuerza que frena el advenimiento del anticristo, o de obstáculo que impide el desencadenamiento de Satán o, en términos de Achever Clausewitz, de «fuerza que frena la escalada a los extremos». En este sentido, estaríamos ante un serio candidato a ser el tema principal de ese último libro de Girard, pero, como decimos, es sorprendente que casi ni se le mencione. Benoît Chantre, consciente de ello, se lo hace ver a Girard, quien se disculpa de este modo: «Usted me hace señalar una de mis fallas... Es mi perfil romántico... Mi gran excusa es la escatología. ¿Acaso la escatología es compatible con una resistencia heroica frente al decurso de los acontecimientos?» (Girard, 2010, p. 163).

Girard había dedicado bastante páginas al estudio de este concepto en obras como Aquel por el que llega el escándalo, en la que se refiere al kathechon como ligado al saber que destruye a Satán y que, además, concierne a los que tienen autoridad para actuar. Y allí se preguntaba: «¿Cómo deben actuar los que saben? ¿Cuál es la función que les corresponde a los sacrificios en una perspectiva en la que la verdad está revelada? Esta es la situación moderna». (Girard, 2006, p. 102). Vemos en Girard, por tanto, al kathechon vinculado estrechamente a la situación moderna.

En Veo a Satán caer como el relámpago lo menciona en relación con la comprensión e incomprensión que las potestades de este mundo tienen de la revelación y dice:

El retraso del Apocalipsis tal vez se deba al comportamiento de los individuos que seesfuerzan en renunciar a la violencia y no fomentar el espíritu de represalia.

Contrariamente a lo que Bultmann pensaba, la verdadera mistificación no tiene nada que ver con los automóviles o la electricidad, procede de nuestra tradición religiosa. Modernos como somos, creemos estar en posesión de la ciencia infusa por el solo hecho de bañarnos en nuestra modernidad. Y esta tautología que venimos repitiendo desde hace tres siglos nos dispensa de pensar. (Girard, 2002, p. 240). 
Por último, en Achever Clausewitz, como dijimos, sería el freno inexplicablemente ausente a la omnipresente escalada a los extremos... Creemos, por tanto, que no sería exagerado decir que el concepto de kathechon es la gran preocupación del último Girard y que, a través de él, puede intuirse un conflicto no resuelto, pues, aunque parezca consciente de su imposible vinculación con la Modernidad, la verdad es que Girard no deja de intentar de encontrarle algún sentido moderno.

Es por ello por lo que no sorprende verlo en Achever Clausewitz caer una y otra vez en la tentación de esa tautología de la que, como hemos visto, advertía diez años antes. Una tautología de la que, como decimos, parece ser consciente al recordar sus fallas, pero es tal la abrumadora presencia de huellas que nos lleva a pensar que se había convertido en el callejón sin salida del último Girard.

Y así, por ejemplo, cuando confiesa a Benoît Chantre que todo lo que en él había de moderno y anticristiano lo había abandonado al revisar la crítica a la Epístola a los Hebreos que había realizado en Cosas ocultas desde la fundación del mundo, no puede por menos de ponernos sobre la pista de la puerta falsa que había escogido: «La crítica a un "cristianismo histórico" en pro de una suerte de "cristianismo esencial", que por mi parte había creído captar de modo hegeliano, era absurda. Por el contrario, hay que pensar el cristianismo como esencialmente histórico y Clausewitz nos ayuda a hacerlo» (Girard, 2010, p. 68).

Pero la ayuda que puede ofrecer Clausewitz para dejar de ser modernos, para conseguir dejar de bañarnos en nuestra modernidad, es del estilo de la que escogió el barón de Münchausen para salir de la ciénaga en la que cayera...

Nosotros nos proponemos intentar deshacer el nudo que parece atar la naturaleza moderna de la teoría mimética a la etapa histórica que denominamos Modernidad, es decir, intentar "salvar esa tautología que nos dispensa de pensar», y, aunque reconocemos que para ello podamos resultar un tanto políticamente incorrectos, no podemos por ello olvidar lo que en otro momento dejó dicho Girard: «La cortesía no debe llegar hasta el punto en que nos impida pensar» (Girard, 1996, p. 9).

Vamos, en primer lugar, a recordar rápidamente que, en los primeros siglos del cristianismo, la función de kathechon se atribuyó al Imperio romano, o que, más adelante, se atribuiría al Imperio español; siempre, por tanto, a figuras histórico-políticas capaces de frenar y contener el avance social de fenómenos disgregadores.

Estamos, por tanto, hablando de un concepto vigente en la formación histórica de lo que podemos denominar cristiandad, ese multisecular movimiento civilizador que sucumbiría ante el avance disgregador de, precisamente, la Modernidad.

Es por ello por lo que, cuando Girard expone argumentos como el que acabamos de citar sobre el retraso del apocalipsis (que «tal vez se deba al comportamiento de los individuos que se esfuerzan en renunciar a la violencia y no fomentar el espíritu de represalia»), no deje de asombrarnos su ingenuidad, pues el freno al apocalipsis no puede partir del esfuerzo partisano de unos pocos individuos, ya que las fuerzas que se baten en el fin de una civilización son de magnitud colosal.

Para comprender la escala a la que nos estamos refiriendo vamos a citar un resumen ya clásico de ese fin de la cristiandad en la que la «función-misión universalista de dique o katechon fue desempeñada por el Imperio español». Son palabras del jurista e historiador de la literatura política de las Españas, Elías de Tejada: 
La Cristiandad muere para nacer Europa, cuando ese perfecto organismo se rompe desde 1517 hasta 1648 en cinco fracturas sucesivas. $A$ saber: la ruptura religiosa del luteranismo, la ruptura ética del maquiavelismo, la ruptura política del bodinismo, la ruptura jurídica por mano de Grocio y Hobbes, y la ruptura definitiva del cuerpo místico político cristiano en la firma de los tratados de Westfalia. (Elías de Tejada, 1954, p. 37).

Este esquema parece identificar a Europa con la Modernidad, una identificación que subyace en los escritos girardianos y que es también fácilmente detectable en Achever Clausewitz, donde, además, hay que advertir que siempre que aparecen mencionados países o capitales europeos no se incluya nunca referencia alguna a España, cuestión esta decisiva, pues, si quiere uno aclararse acerca del carácter teológico-político del concepto de kathechon es inevitable acudir al pensamiento español, tal como nos lo recordaba otro jurista eminente y muy citado por Girard, Carl Schmitt:

Es muy importante para la concepción cristiana del Imperio, que, conforme a la creencia medieval, el cargo de emperador no significase una posición absoluta de poder que absorbe o anula todos los demás cargos, sino una función de kat-echon con tareas y misiones específicas. No es un reinado sobre reyes, ni una corona de coronas, sino un encargo que procede de una esfera completamente distinta a la de la dignidad del reino. Por ello, el pensamiento político español de los siglos XVI y XVII es pura teología política y ayuda a entender el espectáculo, único en Occidente, de una sociedad, al menos parcialmente "antimaterialista". (Schmitt, 1979, p. 42).

En efecto, la España de los siglos XVI y XVII se agotó en un esfuerzo sin parangón por mantener, a nivel planetario, esa concepción cristiana del imperio en la que pudieran pervivir los ideales de la cristiandad. Curiosamente, esta es una referencia histórica que no mereció por parte de Girard más atención que la siguiente frase, frase que acompaña el argumento que plantea a Benoît Chantre sobre la brutalidad del imperio napoleónico: «La idea de imperio, tan vieja como Carlomagno, muy pronto resultó averiada... ¡No digo que hubiera que quedarse en Carlos V! Sin embargo, nos hace falta pensar la mutación que se produjo en esos dos siglos» (Girard, 2010, p. 256).

Reflexión harto significativa, pero que resulta un hápax en la obra girardiana... Reflexión que, de todos modos, continúa en los términos que siguen:

De hecho, para ir directamente a mi sentimiento, pienso que la idea europea se refugió en el Vaticano, más que en París, Berlín, Viena o Moscú. Entre el papado y el imperio, ganó el papado. Y conforme se volvió un fenómeno planetario a partir de Juan Pablo II, la idea europea es lo que ahora se dispersa por doquier. La idea europea tal como los papas la defienden en nuestros días con testarudez, es la identidad de todos los hombres. Pero atención: una identidad recobrada por una razón capaz de integrar lo divino que esa identidad supone. Nos resta esperar que la Iglesia siga en ese lance. (Girard, 2010, p. 256). 
Atendamos con sumo cuidado a este párrafo, pues Girard acierta plenamente: ¡claro que «nos hace falta pensar la mutación que se produjo en esos dos siglos»!, y es que lo que ahí se esconde es el chivo expiatorio sobre el que se levanta la Modernidad, chivo expiatorio que, si se revela, obliga a trastocar paradójicamente el sentido que propone al desarrollo histórico del cristianismo.

Me explico: Girard desconoce dicho chivo expiatorio, y no lo decimos solo por el olvido de mencionar a Madrid al referirse a «la idea europea», sino porque ignora que en «ese lance» ya había estado la Iglesia hace cuatro siglos y que fue al abandonarlo cuatro siglos atrás cuando la idea europea encontró refugio en el Vaticano... El pasado, por tanto, se nos aparece por delante.

Veamos, para ilustrar esta paradoja, lo que ocurrió en el año 1635. Después de más de mil años de desarrollo, la cristiandad, impulsada por el Imperio español, había empezado a hacerse presente en los cinco continentes, y no habría hecho falta, por tanto, esperar a Juan Pablo II para que se hubiera consolidado a nivel planetario esa identidad católico-romana de «una razón capaz de integrar a lo divino». Los estudios del colaborador de esta publicación, David Atienza, sobre la presencia española en la isla de Guam son una clara muestra de lo que estamos diciendo.

Es decir, nada hubiera impedido que el catolicismo se hubiera implantado en todo el planeta si no hubiera surgido en el corazón del continente europeo una vuelta a planteamientos previos a ese proyecto planetario de alcanzar la profética imagen de un solo pastor y un solo rebaño (Jn 10, 16).

En efecto, los príncipes alemanes, celosos de sus privilegios medievales y ante el temor que suponía para sus intereses la presencia universalizante y modernizadora de Carlos V, decidieron comprar la mercancía del argumento religioso que les suministraba el rebelde Lutero para así poder desafiar la rígida ley de vasallaje que les sometía a su señor y emperador. Una mercancía que también sirvió en Inglaterra para justificar los caprichos de Enrique VIII, que, esta vez ante el Papa, siguió la misma senda rebelde.

La monarquía católica o hispánica se vio envuelta, por su lado, en la defensa de los intereses europeos de la dinastía Habsburgo y desarrolló durante dos siglos un esfuerzo ciclópeo por mantener las bases de un catolicismo universal donde se mantuviera la distinción de poderes entre el papado y el imperio, ya que, en los territorios en los que triunfó la apostasía protestante, el poder político y el religioso acabaron unificados en la misma persona.

Llegamos pues al año 1635, en la mitad de la guerra de los Treinta Años, en que se desataron en el continente europeo todas las tensiones acumuladas por las posiciones antes mencionadas. Es un año en que todo está en espera de resolución y nada está, en última instancia, decidido. La rama oriental de la famila Habsburgo había pedido desde Viena y Praga ayuda a sus familiares españoles, y el bisnieto del emperador, Felipe IV, había decidido entrar en el conflicto para salir en su apoyo. El continente entero entra en liza y la aportación hispana parece inclinar la balanza hacia el lado católico, aunque ese año de 1635 iba a producirse un cambio insólito que iba a determinar el futuro de Europa y del orbe y el nacimiento, en fin, de la Modernidad. La católica Francia, contra toda respetabilidad político-religiosa, decide entrar en guerra con España y apoyar los intereses protestantes, y hace que, en Madrid, Felipe IV diga el 2 de junio ante el Consejo de Estado, lo siguiente: «Contra Dios, contra ley, contra naturaleza, ha roto el Rey de Francia conmigo la guerra... Este rey sin pro- 
testarme nada ni avisarme cuando yo trataba de apretar a los herejes me ha roto la guerra por favorecer la herejía» (Elliot, 2004, p. 539).

Hace ya unos años un estudioso español de este momento histórico decía también esto otro:

Porque el enemigo estaba enfrente. Un enemigo que no era, como podríamos pensar hoy simplemente, Francia. Francia es un instigador, un instrumento contra el cual el publicista de 1635 casi nunca acierta a sentir odio. Lo que hace estremecerse de repulsión las entrañas del español de 1635 no es la mera posibilidad de un triunfo francés. Es lo que ello representaría; es la renuncia definitiva a restaurar la unidad espiritual de Europa; es la quiebra de la Paz Austríaca, de la paz de la Cristiandad; es la galopada victoriosa de los herejes; es el triunfo del estado neutral y agnóstico sobre la comunidad política servidora de fines trascendentes; es la subversión de un providencialismo firmemente sustentado; y es también - ¿por qué no decirlo?-el temor al fracaso del orgullo de estirpe, de la soberbia española. Todo esto es lo que moviliza a radice al español de 1635, desde el Conde Duque al último soldado de Flandes. (Jover, 2003, p. 445).

Vemos, por tanto, que, siguiendo a este autor, en 1635 «parece presentarse de forma ya insoslayable un drama aplazado a lo largo de la Baja Edad Moderna, el drama de la modernidad entre la pretensión de una Catolicidad universal defendida por España y el sistema leviatano, moderno, de equilibrio entre Estados desconocedores de toda superior norma ética» (Jover, 2003, p. 408).

Para nosotros, sin embargo, el asunto va todavía más allá, pues lo que aquí aparece es nada más y nada menos que la clara decantación por parte del Vaticano en contra de las aspiraciones universalistas del catolicismo y en pro de la salvaguarda de intereses representados por un nuevo concepto político, o, mejor dicho, por un concepto político que empieza inevitablemente a adquirir una nueva dimensión semirreligiosa, el concepto de nación.

Es decir, va a ser la Iglesia la que favorezca la aparición de un nuevo ídolo cuya adoración va a tener un largo desarrollo en la era moderna, y ese ídolo va a ser la nación, una realidad política elevada a un rango desconocido hasta la época, pues todavía no había tenido oportunidad de enfrentarse a un rival como eran las exigencias político-morales de las aspiraciones universales del catolicismo, es decir, no había tenido todavía necesidad de ejercer su naturaleza cainita. Ese nuevo ídolo, que va a comenzar su andadura en estos momentos en distintas partes de Europa, va a tener como clara protagonista a Francia, ya que ¿quién sino Francia determinó que no se llevara a cabo el fin del sueño universalista del catolicismo en el siglo xvII? A este respecto, hay que recordar el lamento que el barón Ludovico Pastor dejó escrito en su famosa Historia de los papas: «Es en gran manera funesto que dos cardenales (Richelieu y Mazarino) contribuyesen de un modo decisivo a arrebatar a la Iglesia romana el triunfo final de una lucha secular y que esta mudanza histórica procediese de Francia, tan cara a Urbano VIII, y por la cual Sixto V había sacrificado su vida» (Pastor, 1945, vol, XXVII, t. XIII, p. 54).

La actitud poco honorable de Francia hacia la monarquía católica, que empieza a volverse tradición en los días de Carlos V y Francisco I, se manifiesta claramente en 1635 conformando un momento decisivo para el futuro de Europa del que quizá no seamos ahora lo suficiente- 
mente conscientes, pero que en la España de la época se entendió en clave eminentemente religiosa y, como afirma Jover, en un doble sentido: «De una parte, en cuanto defensa de la Cristiandad frente a la movilización de los ejércitos del Norte. De otra, en cuanto tenaz resistencia de un orden cristiano, guardián del bien común y de la fe pública, atento a la legitimidad de sus Príncipes, frente a las artimañas de los conocidos en la época como "políticos del tiempo"» (Jover, 2003, p. 180).

Aunque tambien es verdad que Richelieu no fue la única persona en frenar las aspiraciones de una monarquía católica que, no en vano, ha pasado a la historia con el sobrenombre de monarquía in ecclesia, dado su apoyo e incontestable servicio a la Iglesia. Como decia Girard, «la idea europea encontró refugio en el Vaticano». En efecto, desde el mismo Vaticano también se vio en ocasiones con recelo la expansión planetaria llevada a cabo por los españoles. Y así, por ejemplo, tras el proyecto de conquista de China del padre Alonso Sánchez en 1580, Roma se había apresurado a organizar una institución que centralizase la expansión del catolicismo en todos los continentes sin la ayuda de ningún poder temporal; sería la futura Sagrada Congregación para la Propaganda de la Fe, que el 6 de enero de 1622 echaría andar bajo el papa Gregorio XV.

Resulta revelador que el patrono de esta congregación sea un capuchino alemán que murió mártir en Suiza ante los protestantes, y sin embargo, en una confesión en la que el mayor número de los contigentes es de habla hispana, la gran misionera de Nuevo México, redactora de la vida de la Virgen más leída de la historia, Ciudad mística, y una de las mujeres más influyentes del siglo xVII, pues fue durante años confidente de Felipe IV, no haya podido ser todavía ni canonizada, ni siquiera beatificada, debido a los frenos que por siglos ha impuesto a su causa la Iglesia francesa.

Pero así se ha construido esa Modernidad a la que Girard no deja de vincular con el fracaso del cristianismo (Girard, 2010, p. 163), elevando a los altares la idea de Europa y condenando al proyecto universalista de la cristiandad a ser el protagonista de la leyenda negra, concepto que no hace falta casi traducir a ningún idioma, pues automáticamente se identifica en la mayoría de ellos con la leyenda negra antiespañola.

El último libro de Diego Saavedra Fajardo, embajador plenipotenciario español en los tratados de Westfalia de 1648, en los que se establece ya la naturaleza política de la Europa moderna, se titulará precisamente Locuras de Europa, título que podría servir para ilustrar la afirmación de hace unos años del escritor sueco Sverker Arnoldson: «La leyenda negra de España es la mayor alucinación colectiva de Occidente, la leyenda ilustrada de Francia es la segunda» (Arnoldson, 1960, p. 24).

Pues, en efecto, la idea moderna de nación, que en el protestantismo comenzó a participar de características propiamente heréticas, fue aumentando en el catolicismo sus tintes idolátricos para, a través de su unión con el concepto de Estado, alcanzar en la Revolución francesa carácter casi de religión oficial.

Y la expansión que llevó a cabo de esos ideales ilustrados el dios de la guerra Napoleón es la que le llevará a Girard a certificar su confusión entre cristianismo, modernidad y Europa, pues es comentando ese momento cuando llega a decir: «Pero acaso sea ya demasiado tarde. El cristianismo histórico fracasó y con él la sociedad moderna» (Girard, 2010, p. 162).

A partir de ahí, pues, el punto de vista de Girard sobre el apocalipsis en el mundo actual está servido. Aunque de la guerra absoluta, a la que considera resultado inevitable del producto de 
dos idolatrías nacionales, es de donde surgirá la necesidad de elaborar una histora mimética. Vamos a constatarlo en los propios textos de Girard, mejor dicho, en Achever Clausewitz.

El concepto de historia mimética aparece en Achever Clausewitz en dos ocasiones y en ambas le sirve para referirse al cara a cara franco-alemán, lleno de odio y fascinación a la vez, y origen de la escalada a los extremos que, según Girard, tenemos por delante (Girard, 2010, p. 66).

En un caso se menciona ese concepto a la hora de proponer como salida al conflicto «no solo mirar a Alemania con ojos franceses, sino también a Francia con ojos alemanes» (Girard, 2010, p. 260). En el otro se plantea la tarea de la necesidad de elaborar una historia mimética (Girard, 2010, p. 75) . Veámoslo:

Girard está hablando del origen de la guerra absoluta y comenta a Benoit Chantre que Francois Furet tiene razón respecto a Ernst Nolte, ya que el primero piensa que ese origen hay que buscarlo en la Primera Guerra Mundial, y no en la segunda, que es lo que piensa Nolte y que sería, según Girard, «una manera de conjurar el apocalipsis apurando su decurso». Y continúa:

Furet tiene razón; pero habría que remontarse aún más atrás para encontrar ese origen, a Napoleón e incluso a Luis XIV. Es lo que dice Clausewitz, y no se equivoca. Habría que remontarse a ese odio de Francia y de Prusia hacia el Sacro Imperio Romano Germánico [...]. No podemos abrir aquí un campo de estudio inmenso. Está pendiente la construcción de una Historia Mimética, estoy convencido de ello: nos ayudaría a comprender los desafíos de nuestra época.

Podemos ver aquí, por tanto, el momento en el que surge en el pensamiento de Girard la necesidad de una historia mimética, y ese momento es en el que, en busca del origen de la guerra absoluta, comienza a remontarse más allá de la guerra terrible entre «dos idolatrías nacionales» (Girard, 2010, p. 255) hasta detener el discurso en Luis XIV y el Sacro Imperio Romano Germánico. Es decir, el momento en el que se abre un «campo de estudio inmenso» es el momento en el que debería haber entrado en escena el proyecto universalista de la cristiandad que llevó a cabo el Imperio español.

Vemos, por tanto, que ese campo inmenso de estudio de la historia mimética no es sino el territorio del chivo expiatorio sobre el que se levanta la Modernidad y que Girard desconoce de un modo tan significativo. Por otro lado, una autora que se ha dedicado a estudiar magistralmente este tema, recurre, sin embargo, al resumir su diagnóstico, a las intuiciones del maestro francés.

Dos son las razones principales que explican la perpetuación de la hispanofobia y sus tópicos. La primera es su papel en el aparato de autojustificaciones tanto de las naciones protestantes y sus correspondientes iglesias, como de la llustración y el liberalismo. Las naciones y las religiones que se formaron contra el Imperio español no pueden prescindir de la leyenda negra porque se quedarían sin Historia. Y una vez muerto el Imperio, la leyenda negra se transforma de manera suave y natural en el mecanismo del chivo expiatorio. (Roca, 2017, p. 474). 
Para Girard, por el contrario, al confundir cristianismo, modernidad y Europa, el chivo expiatorio era, evidentemente, otro: «Es muy sintomático que sea el Sacro Imperio Romano Germánico el que haya cumplido el rol de chivo expiatorio durante más de tres siglos: ello implicaba la única posibilidad política de Europa, y es en torno y en contra de esa reliquia carolingia que los europeos se mataron unos a otros» (Girard, 2010, p. 177).

Los lectores españoles deberemos tener bien claro, por tanto, que cuando Girard habla de Europa no incluye en ella a España. Europa está formada por la herencia del Sacro Imperio Romano Germánico y, por supuesto, Francia, a la que no deja de atribuir como principal error sus pretensiones de ser imperio (Girard, 2010, p. 140).

Ya vimos cómo, en un contexto napoleónico, Girard afirmaba que «la idea de imperio, tan vieja como Carlomagno, muy pronto resultó averiada» (Girard, 2010, p. 256). Pero era una idea de imperio que resultó averiada para los franceses, cuya historia moderna daría para un muy sustancioso capítulo de la historia mimética, pues su deseo por el imperio siempre ha sido un deseo por el imperio de los otros, ya sean estos españoles, austrohúngaros, rusos, estadounidenses..., un deseo que no ha dejado de tener su reflejo paródico en la emblemática grandeur.

Pero en el proceso que llevó a convertir al Imperio español en chivo expiatorio no solo encontramos la relación modelo-obstáculo que reflejan las envidias francesas, sino el levantamiento de los escándalos que han necesitado las falsas acusaciones de que ha sido objeto para legitimar la autoafirmación que define al espíritu de la Modernidad y que tan estrechamente se encuentra unida al fenómeno del nacionalismo. Por ello, es un chivo expiatorio con mucho futuro todavía, ya que, en un contexto de ambiciones globalistas, resultará imprescindible la rancia pestilencia de ese primer proyecto global del planeta para que pueda ensalzarse el delicioso aroma de la actual globalización.

Vamos a terminar recogiendo en una gran figura histórica varios de los aspectos que hemos abordado en nuestro artículo. Esa figura es la de un europeo, aunque polaco, san Juan Pablo II, quien, en su Mensaje con ocasión del 50 aniversario del final de la Segunda Guerra Mundial, hizo referencia a los peligros del culto idolátrico al que pueden acabar abocadas las naciones. San Juan Pablo II, por otro lado, beatificó al último emperador del Imperio austrohúngaro, el muy católico Carlos de Austria, de quien había recibido él mismo su nombre de pila al habérselo puesto su padre como homenaje a tan carismática figura.

Y, por último, san Juan Pablo II dió el 9 de noviembre de 1982 en la catedral de Santiago de Compostela el famoso grito «iReencuentra tu alma, vieja Europa!», grito que ha suscitado abundantes estudios, como los que se recogen en el volumen colectivo editado por René Luneau y titulado Le reve de Compostelle. Vers la restauration d'une Europe chrétienne?

En este libro, autores como Paul Ladriere, Paul Blanquart, Jean Delumeau o Jean-Pierre Manigne parecen estar de acuerdo en pensar que la idea de Europa de Juan Pablo II era arcaica, pues pretendía que el cristianismo del primer milenio sirviera de modelo para la evangelización del tercero. Es lo que denominan «el equívoco de los orígenes», pues, a su parecer, la idealización del pasado altomedieval y el silencio absoluto sobre la Reforma no daban respuesta a las cuestiones que plantea la Europa moderna (un retorno a lo arcaico que curiosamente puede encontrarse también en las últimas páginas de Achever Clausewitz con las Ilamadas de atención a la actualidad que, para Girard, recuperan los siglos VII-IX o la batalla de Poitiers y las Cruzadas...). 
Lo lógico sería pensar, pues, que estos autores, al referirse al idealizado pasado altomedieval y al silencio absoluto sobre la Reforma, fueran conscientes del olvido de san Juan Pablo II acerca de la defensa del catolicismo que llevó a cabo el Imperio español. Pero esa lógica no permitiría otra lógica, la que impone condenar al Imperio español a ser chivo el expiatorio de la Modernidad. De ahí que el argumento que planteen estos autores esté hecho en los términos siguientes, términos que resumen la opinión de todos ellos acerca de los caminos que debería seguir una inculturación capaz de facilitar la nueva evangelización: «Probablemente para toda la Europa occidental, y seguramente para Francia, los caminos abiertos hacia los orígenes, hacia el "arcaísmo" de la identidad cultural y religiosa, están guardados por demasiados demonios para que no nos sintamos inquietos cuando se nos convoca a ellos» (Luneau, 1993, p. 180).

La coincidencia con los argumentos que llevamos desarrollando en este escrito nos lleva a decir que puede que exista la posibilidad de redimir al chivo expiatorio del Imperio español, y esa posibilidad sería que se pudiera llegar a entender el gesto de san Juan Pablo II como un exorcismo capaz de expulsar los demonios que guardan la identidad cultural y religiosa de Europa, posibilidad que, a nuestro parecer, solo se alcanzará el día en que se atienda al significado de la basílica desde donde fue lanzado el grito.

\section{Referencias bibliográficas}

Arnoldson, Sverker (1960). La leyenda negra, estudios sobre sus orígenes. Göteborg, Suecia: Göteborg Universitas.

Elías de Tejada y Spínola, F. (1954). La monarquía tradicional. Madrid, España: Rialp.

Elliot, John H. (2004). El conde duque de Olivares. El político en una época de decadencia. Barcelona, España: Crítica.

Jover, J. M. (2003) [1946]. 1635, Historia de una polémica y semblanza de una generación. Madrid, España: CSIC.

Girard, R. (1996). Cuando empiecen a suceder estas cosas. Madrid, España: Encuentro. Girard, R. (2002). Veo a Satán caer como el relámpago. Barcelona, España: Anagrama. Girard, R. (2006). Aquel por el que llega el escándalo. Madrid, España: Caparrós. Girard, R. (2010). Clausewitz en los extremos. Buenos Aires, Argentina: Katz Editores. Luneau, R. (1993). El sueño de Compostela, ¿hacia una restauración de una Europa cristiana? Bilbao, España: Descleé de Brower.

Pastor, L. (1945). Historia de los papas. Barcelona, España: Gustavo Gili.

Roca Barea, E. Imperiofobia y leyenda negra. Madrid, España: Siruela.

Schmitt, C. (1979). El nomos de la tierra en el derecho de gentes del ius publicum europaeum. Madrid, España: Instituto de Estudios Políticos. 